\title{
Conhecimento, Atitude e Prática do Auto Exame da Mama e do Exame de Mamografia em Usuárias dos Centros de Saúde do Municipio de Campinas
}

\author{
Autor: Luiz Alberto Barcellos Marinho \\ Orientadora: Profa. Dra. Maria Salete Costa Gurgel \\ Co-orientador: Prof. Dr. José Guilherme Cecatti
}

Dissertação de Doutorado apresentada ao curso de Pós-Graduação da Faculdade de Ciências Médicas da Universidade Estadual de Campinas (UNICAMP), área de Tocoginecologia, em 14 de dezembro de 2001.

O câncer de mama é considerado um problema de saúde pública em quase todos os países. O efeito devastador causado por esta neoplasia tem motivado a criação de programas de educação em saúde a fim de conseguir seu diagnóstico precoce quando as chances de cura são maiores. O objetivo deste estudo é avaliar qual o conhecimento, a atitude e a prática do auto exame das mamas e do exame de mamografia entre as mulheres que se utilizam do serviço municipal de Campinas (SP) e identificar quais as barreiras para que a população feminina tenha acesso à realização de procedimentos que auxiliem no diagnóstico precoce do câncer de mama. Foram entrevistadas 663 mulheres de 13 Centros de Saúde municipais, através de um inquérito CAP (Conhecimento, Atitude e Prática), incluídas de forma aleatória, de maneira que no estudo estivessem representadas mulheres residentes tanto em áreas mais favorecidas como em locais mais distantes no município de Campinas (SP). Para análise dos resultados, as respostas das mulheres foram descritas quanto ao conhecimento, atitude, prática e suas respectivas adequações como previamente definido. Esta adequação comparada entre as categorias das variáveis de controle através do teste $\chi^{2}$. Os resulta- dos obtidos mostraram que o conhecimento e a prática do auto-exame das mamas e do exame de mamografia foram inadequados, embora a atitude frente a estes dois procedimentos tenha sido adequada. O estudo também mostrou que, para a realização do autoexame das mamas, o esquecimento desta prática é a principal barreira para que não seja realizada, enquanto a principal barreira para não se fazer a mamografia foi a falta de solicitação deste exame por parte dos médicos que atuam nos Centros de Saúde. Mostrou ainda a associação entre a adequação da prática do autoexame das mamas com as variáveis de controle: idade maior que 50 anos, escolaridade maior que 5 anos, trabalho fora de casa e renda superior a 5 salários minimos. Quanto a mamografia, houve associação entre a adequação da atitude e as variáveis escolaridade igual ou maior a 5 anos e ser casada. Houve também associação entre a adequação da prática da mamografia e as variáveis trabalho fora e renda da família igual ou superior a 5 salários mínimos.

Palavras-chave: Mama: câncer. Auto-exame de mama. Mamografia.

\section{Alterações Endometriais em Pacientes com Câncer de MamaTratadas com Tamoxifeno: Análise por Ultra-sonografia Transvaginal, Histeroscopia e Histopatológico}

Autor: Francisco Edson de Lucena Feitosa

Orientador: Prof. Dr. Sérgio Ferreira Juaçaba

Dissertação de Mestrado apresentada ao programa de Pós-graduação stricto sensu do Departamento de Cirurgia da Faculdade de Medicina da Universidade Federal do Ceará, em 14 de dezembro de 2001.

Objetivos: Determinar a prevalência de alterações endometriais e os achados histopatológicos mais freqüentes em mulheres com câncer de mama tratadas com tamoxifeno durante cinco anos. Avaliar sensibilidade, especificidade, valor preditivo positivo e negativo e razão de probabilidade da ultra-sonografia transvaginal e da histeroscopia quando comparadas com o histopatológico do endométrio.

Método: Estudo transversal, com trinta pacientes que usaram tamoxifeno por 5 anos, em que se realizou ultra-sonografia transvaginal, histeroscopia, biópsia de endométrio e análise histopatológica de todas as pacientes.

Resultados: A prevalência geral de alterações endometriais foi de $36,6 \%$. Os achados mais freqüentes foram a atrofia cística $(46,6 \%)$ e os pólipos endometriais $(26,6 \%)$. Através de Curva ROC determinou-se que o melhor ponto de corte da medida da espessura do endométrio através da ultra-sonografia transvaginal foi $8 \mathrm{~mm}$. Esta apresentou sensibilidade de $72,7 \%$, especificidade de $78,9 \%$, valor preditivo positivo de $66,6 \%$ e negativo de $83,3 \%$ e razão de probabilidade de 3,4 . A histeroscopia apresentou sensibilidade de 90,9\%, especificidade de $68,4 \%$, valor preditivo positivo de $62,5 \%$ 
e negativo de $92,8 \%$ e razão de probabilidade de 2,8 . Conclusão: As pacientes com câncer de mama que utilizaram tamoxifeno por longo período apresentaram elevada freqüência de alterações endometriais; as mais comuns foram a atrofia cística e os pólipos. A ultrasonografia transvaginal apresentou maior taxa de falso-positivo $(42,1 \%)$ quando se utilizou o valor de $5 \mathrm{~mm}$ como ponto de corte da espessura do endométrio, porém melhorou-se a especificidade, o valor preditivo positivo e negativo quando utilizou-se a medida de 8 $\mathrm{mm}$, obtida através da confecção de curva ROC.

Palavras-chaves: Tamoxifeno. Endométrio: avaliação. Histeroscopia. Neoplasia mamária. Mama: câncer.

\section{Dopplerfluxometria Aplicada ao Duto Venoso no Primeiro Trimestre: Ênfase na Detecção das Aneuploidias}

Autor: Carlos Geraldo Viana Murta

Orientador: Prof. Dr. Antônio Fernandes Moron

Co-orientador: Prof. Dr. Márcio Augusto Pinto Ávila

Tese apresentada à Universidade Federal de São Paulo - Escola Paulista de Medicina, para obtenção do Título de Doutor em Medicina, em 19 de novembro de 2001.

Objetivo: Investigar a aplicabilidade da dopplerfluxometria do duto venoso, tanto em situação de normalidade quanto na detecção das aneuploidias, entre a $10^{\mathrm{a}} \mathrm{e}$ $14^{a}$ semanas de gestação. Propõe-se também novo cálculo de risco para a síndrome de Down, bem como a análise da reprodutibilidade do Doppler do duto venoso.

Pacientes e métodos: 606 fetos foram submetidos prospectivamente à dopplerfluxometria do duto venoso e à medida da tanslucência nucal. Em 157 casos realizouse estudo citogenético, e, em 449 casos, o resultado teve como base o fenótipo do recém-nascido. Na análise estatística foram predominantemente utilizados: o teste paramétrico $t$ de Student, análise de variância e a regressão linear. Posteriormente, calculou-se: sensibilidade, especificidade, valor preditivo positivo e negativo, probabilidade de falso-positivo e razões de probabilidades. Adicionalmente, a forma geométrica e o padrão de fluxo normal do duto venoso foram analisados.

Resultados: Entre a $10^{\mathrm{a}}$ e $14^{\mathrm{a}}$ semana, definiu-se a nova forma geométrica do duto venoso como cilíndrica. $\mathrm{O}$ fluxo não variou entre 11 e 13 semanas, e a reprodutibilidade foi considerada satisfatória. Ocorreram 37 casos de aneuploidias. Nesses, o fluxo no duto venoso durante a contração atrial foi ausente ou reverso em 33 casos (sensibilidade de 89,2\%). Entre os fetos normais $(n=569)$, apenas $8(1,4 \%)$ apresentaram fluxo anormal. Ao se considerar os 23 casos de sindrome de Down, o fluxo no duto venoso foi anormal durante a contração atrial em 21 casos (taxa de detecção de 91,3\%, especificidade de 98,6\%, valor preditivo positivo e negativo de $72,4 \%$ e $99,6 \%$, respectivamente; e razão de probabilidade positiva, e negativa, de 64,9 e 0,1, respectivamente).

Conclusões: A estimativa do fluxo no duto venoso entre a $10^{\mathrm{a}}$ e $14^{\mathrm{a}}$ semanas de gestação deve ser aplicável como teste de rastreamento de segundo nível das anomalias cromossômicas, reduzindo a necessidade de procedimentos invasivos derivados exclusivamente da medida da translucência nucal de $5 \%$ para menos de $0,5 \%$, com apenas uma pequena diminuição da sensibilidade (aproximadamente de 10\%). Sugere-se a possibilidade de novo cálculo de risco para trissomia do $21 \mathrm{com}$ base na dopplervelocimetria do duto venoso. Utilizando-se o programa de risco da Fetal Medicine Foundation como risco basal, ter-se-ia um fator multiplicador de 0,1 (razão de probabilidade negativa), caso de fluxo no duto normal, ou de 65 (razão de probabilidade positiva), caso de fluxo anormal. Depreende-se, assim, novo risco fetal.

Palvras-chave: Dopplerfluxometria. Duto venoso. Rastreamento. Anomalias cromossômicas. 